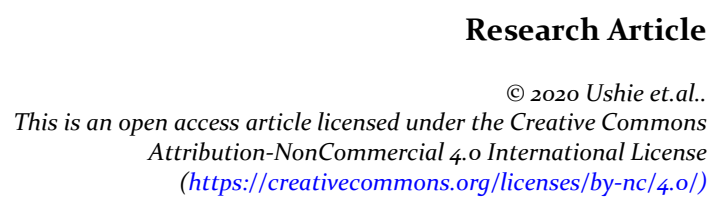

Received: 19 May 2020 / Revised: 29 June 2020 / Accepted: 1 July 2020 / Published: 10 July 2020

\title{
Population Control and Family Life Education in South-South, Nigeria
}

\author{
Doris Emmanuel Ushie
}

Sunday David Edinyang

Austin Robert Igwe

Joy Anthony Ukam

\section{Abigail Ojong Ejoh}

\author{
Department of Social Science Education, \\ University of Calabar, Etagbor, \\ PMB 1115 Calabar 2018, Nigeria
}

DOI: https://doi.org/10.36941/mjss-2020-0043

\begin{abstract}
The purpose of this paper was to explore the importance of family life education in South-South Nigeria as regards population growth. An initiative has delved into the philosophical conceptions of schooling and the population in family life. It also presents an overview of the positive effects of education in family life. Today, population growth in South-South Nigeria presents many problems, including; poverty and unemployment. The paper accounts for ways in which family life education will play a significant role in improving the population's management. Finally, the article suggests that Growth and Development in adolescence is an integral component of family life education. Strengthened educational efforts should be undertaken in areas such as self-understanding, guardian relationships, jobs, obligations, feelings, stress management, dating, romance, maturity development, and enhancements to sexuality.
\end{abstract}

Keywords: Family life education, Population, Fertility, Population distribution

\section{Introduction}

Young people in South-South Nigeria and throughout society are in daily need of a full and safe improvement: a supportive and secure life and family; a sense of their bodies, including their passion and physical weaknesses, motivating sexual activity and replication; a knowledge of people's problems and how they might be affected by these problems; and details. For these advantages, youth predominate in employment, have personal satisfaction and connections, and contribute to their nations ' economies and prosperity. We face interfered work, individual disabilities, ill wellbeing, and loss of currency chances.

Family education is "an educational method aimed at helping individuals to mature and mature in their physical, enthusiastic and moral life, as well as at social relations in the social and social context of their families and communities" by the International Planned Parenthood Federation (IPPF, 1985). Family life preparation will enable people to improve their physical, emotional, 
enthusiastic, and moral standards.

The number of teenagers in Asia, Africa, Latin America, and most of them goes to colleges is the highest ever: 1,7 billion people aged 10 to 24 (U.N., 2018). In individual countries, the age of intercourse has deteriorated since the start. The wellbeing and regenerative wellbeing of young people should provide the public with both immediate and long-term benefits. Many smart parents share a childhood dream. They would become fully mature without early puberty, complete studies, postpone the start of sexual encounters until they have established themselves fully, socially, and effectively, and stay away from H.I.V. and others S.T.I.s.

When colleges do not talk about home life and populace issues, they develop the capacity to influence learner training, personal satisfaction, relationships, and ultimately economics and performance in countries. Young female pregnant women, for instance, often leave school. Sometimes young guardians are not able to work without a school testament or only land low-paid positions that do not help the family successfully (Adediwura \& Tayo, 2007).

\section{Objectives of Family Life Education}

The objectives of education for families are as set out by Chiappetta and Koballa Jr. (2006);

i. Family Life Education will empower people to understand the importance of the family as the essential bio-social gathering in the public arena.

ii. This assists in understanding and clarifying family relationships, family structure, and family life patterns.

iii. Consider problems associated with a sexual relationship, requirements for maturity, family relationships, before marriage, and age of bearing for children.

iv. To handle the relative advantages of littler family sizes and their impact on personal satisfaction for both the individuals concerned, the more distant family, and the country as a whole.

v. Broadcasting free communities and family laws.

\section{Challenges of Family Life Education}

Family life education problems, according to Alazzi (2013) including:

i. The internet and the World Wide Internet pose new challenges for training in family life. These innovations will probably supplant a kind of customary instruction in family life. Significant problems need to take into account the unwavering consistency and credibility of the open data and its feasibility.

ii. Developing issues such as computer-mediated interactions and using the sexualized network involves re-examination.

iii. If their development and implementation are accompanied by social and educational policies and political decisions, the programs themselves will not be sufficient.

iv. Qualified teachers are vital to the achievement of family life instruction, as they hold significant responsibilities in molding insightful knowledge and interfacing with families. In the field of family life instruction in Nigeria, there is, by all accounts, the absence of satisfactorily trained staff.

v. A further measure of family life training is insufficient financing. In other cases, the programs are just available to the people who can afford the cost of it, even unavailable to the people who need it the most (Yasin, 2015).

\section{Core Messages in Population and Family Life Education}

In the Nigerian Population Education Program, the center messages include:

1. Family size and government support: A small family size increases personal satisfaction in 
nutrition, education, housing, wellbeing, clean drinking water, training, relaxation/amusement, investment funds, parental care, and care.

2. Delayed marriage: Delayed marriage has many attractive points for the woman, the group, and the region. Women who postpone marriage will have shorter periods of pregnancy, and will thus continue to have fewer children than women who marry sooner. Likewise, young people who delay marriage would continue to have smaller families, be able to pursue selffulfillment and job-gaining schooling, and improve the health of parents, brothers, and sisters.

3. Responsible parenthood: It involves managing the family size, spacing children, caring for the elderly, and understanding the biology of human reproduction, among other things. Having fewer and more spaced-out births improves the wellbeing of mother and child, and offers more incentives for women to share social and economic responsibilities.

4. Change of population and enhancement of assets: This message combines situation and community elements of the section and their interrelationship with the world, assets (universal and human), and financial advancement. Similarly, it recalls the impacts of women's improved status for advancing populace growth.

5. Population-related convictions and qualities: This involves an clarification of ace natalist, socio-social values, and varieties, such as children's inclination, early marriage, colossal family, mature age welfare, and customary beliefs about women's work.

\section{Variables Influencing Population Distribution in Nigeria and Africa}

According to Elster (2007), multiple variables are liable for the unbalanced distribution of the population in Nigeria and Africa. Elements that impact the circulation of the populace are physical, chronic, and financial elements. Although various components add to it, a definitive factor in the appropriation of populations is monetary potential as individuals live just where they can find ways to acquire a living.

A. Physical factors which influence the distribution of population in Nigeria and Africa

1. Rainfall: The precipitation measurement can represent divisions between densely populated regions and sparsely populated regions.

2. Soils: Additionally, important is the effect of soil quality on populace conveying. The predominance of deplorable soil conditions has made for settlements a few zones such as the entrance fields, the swampy Niger Delta, and the Nigerian coast's sterile sand and seashore edges cold.

3. Disease: The threat of tsetse fly spreads trypanosomiasis among steers and dozing affliction among individuals. It is a significant physical factor affecting population appropriation in the tropics, especially in the African continent. Individuals may switch away from areas where the disease has a high prevalence.

4. Natural vegetation: thick woodland repulses populations; light woods and meadows draw in and support small communities.

5. Mineral assets: Individuals typically move to areas where many minerals are available, even if the weather is harsh. Models blossom around Jos.

B. Historical factors are influencing Nigeria and Africa's population distribution.

Reported developments in different parts of the planet decreased the population. These advances include:

1. Exchange of slaves: In the eighteenth and nineteenth centuries, between 10 and 15 million Africans diverted as captives to Europe and America. The areas that suffered slave-exchange-related removal include the West African, Southern, and Western Yorubaland Middle Belt and so on.

2. Inter-tribal war: The war between ancestral wars in Yorubaland in the nineteenth century prompted numerous people to die. Somalia, Liberia, and Sierra Leone are 
currently being exhausted due to conflicts from the populace.

3. Religious Persecution: Abused people fled abroad after the Maltasine Riot in Nigeria in northern Nigeria. Another consideration is a safe link between the Ibos and a couple of people to the Plateau State territory.

C. Political factors impacting Nigeria and Africa's population distribution

Many of the governmental policies and decisions that have influenced public circulation include:

1. Forest and game reserves: production of timberland and game stores, where settlement and cultivation are unlawful, has given rise to circumstances where a mostly uninhabited region exists next to each other with densely populated areas where individuals experience intense farmland deficiency.

2. Resettlement Plans: People are discretionarily removed from their own countries and resettled under government orders. Individual relocation by large artificial lakes such as Kariba Lake and Lake Kainji has had an remarkable effect on individuals. Similarly, Nigeria 's settlement combination plans for wellbeing or security reasons have had a noteworthy impact on the nation's conveying or redistributing populace.

D. Economic variables affecting Nigerian and African population distribution

In many parts of the world, financial components have become significant in molding populace appropriation. This reflects an perception of mechanical development. Despite the urban emphasis, the major areas of high population thickness in Africa are those of rural districts producing minerals or new export harvests.

For example, throughout West Africa, the significant financial growth focal points are situated within 150 miles of the coast. Open doors for business in either mechanical or rural areas are prominent along the beach where most urban capital communities and important seaports are located. Consequently, it is not surprising that there is a coordinated population migration from the inside to the seaside territories.

Urbanization is another monetary factor that impacts populace circulation in Nigeria and Africa. The vast majority of the transients to the developing urban focuses originate from the blocked rural regions. Considering the rapid speed of urbanization, it is prudent to expect more prominent convergences of individuals in a few financially competitive areas.

Elements impacting the growth of the population:

Increment in populace is also regarded as the pace of population growth. This rate of growth compares between country and country and from one economy to the next. Other than migration, the growth of populations in any country is due to frequent changes in the birth and death rates.

A. Childbirth:

Different components can affect the distinction between various gatherings in the level of fruitfulness:

1. Occupation: individuals with esteemed careers have fewer youths than those with fewer public laws.

2. Income: The higher the level of salary, the lower the level of fruitfulness and, again, the lower the level of pay, the higher the level of wealth.

3. Education: The higher the level of instruction, the lower the rate of wealth goes. Research has shown that in traditional social orders, where maturity increases, preparation also affects the time of marriage, the use of protective measures, and attitudes to the detriment of raising children.

4. Religion: Adherents of particular sects are, for the most part, more educated than Jews or Protestants. Research has shown that Muslims also get higher levels of fruitfulness than non-Muslims. Some strict reunions may also imply the size of the family or the number of spouses required.

5. Urbanization: fruitfulness levels would typically be higher in country regions than those in urban areas. Urbanization is due to some variables that influence lower rates of 
corporate maturity to incorporate the significant expenses of living, social portability, social wages, social classes, employment status, female business, and training.

6. Gender Preference: The status of women has dramatically changed, and thus less focus is put on gender when it comes to raising young people.

B. Rate of Mortality (death):

In simple words, mortality is the phenomenon of death. We calculate the death rate by agreeing on the proportion of the number of passes to the entire population of a region per year, which communicated as X number of individuals per thousand. The rate of death is linked to the degree of financial growth. Demise rates are the lowest in cutting-edge nations and the highest in society-building. The standard variables which impact the price of death include:

1. Social class: As the degree of the eminence of the occupation of a surrendered gathering goes down its rate of demise

2. Race and ethnicity: When a particular racial or ethnic meeting prevails over the other, in general, the lesser gathering will endure more and may have a lower future because of limited chances.

3. Sex Difference: At almost every age, male mortality is higher in various social orders than that of females.

4. Marital status: Wedded individuals will, in general, live longer than single ones.

5. Age: Death rates are by and large among newborn children of less than a year and decrease slowly until the age of 18 when the level is the lowest. After 6o, the rate of death is rising again.

6. Rural-urban contrasts: In urban regions, mortality levels are generally higher than in country zones. Notwithstanding this, rational and technological advancement has increased corporate death rates with improvements such as hygiene, establishing adequate health offices, general wellbeing efforts, and open or free health centers.

C. A Large Population of Interest

1. Larger working population: a more significant population implies more specialists, which will increase monetary yield whenever combined with other essential elements.

2. Expansion of household advertisements: The local market for merchandise and ventures of the people of the country will grow by a considerable population.

3. Diversity of skills: A large population would potentially be accompanied by a good range of talents and abilities. Various professions regulated by the multiple areas and gatherings tackled for expanded and improved development.

4. Strategic and mental fulfillment: more people will be available to shield a nation with a vast population.

5. International glory and respect: a vast community gives a country a sense of meaning and security. It is essential as a country with a large population raises consideration more remarkable than littler-populated nations.

D. Hindrances to a Large People

When the size of a nation's population goes beyond the ideal or average, various impediments will begin to set in even when different variables complement this large population. Accordingly, an overly large population incites the accompanying:

1. Overpopulation: a large population may cause congestion, which may strain social administrations, such as emergency clinics, water, electricity, etc.

2. Food deficiencies: a large non-self-supporting population must import nourishment from various nations, generating an trade irregularity that hurts the country's bringing in.

3. Political strength: The rapid and unregulated growth of the population causes political precariousness as the government does not have the option of meeting the rapidly developing masses' social and financial demands. 
4. Unemployment: a full spectrum of joblessness is put in by trained and less skilled professionals. A large pool of continually unemployed professionals provides social problems such as prostitution, fitted burglaries, and fear-mongering.

5. A massive proportion of dependence: the overpopulation causes a large portion of the relationship. The number of ward individuals to those engaged in dynamic and efficient development would be huge, thereby increasing the ward population quantity.

\section{Relationship between Guidance in the Family Life and Population Growth}

The link between family and population instruction has brought both researchers and policymakers to bear in mind, according to Kuhl, Tsao, and Liu (2003), especially since the mid-1970s. The population's growth rate and the number of people living on earth have risen significantly since the beginning of the nineteenth century. The overall global population has grown ten times as quickly as the rate over the last 10,000 years in the 2oth century. The number of people living increased between seven overlaps in 2010 and 2018. The extent of population growth in the '7os was as remarkable after the Second World War as it was a century ago (Bledsoe, Casterline, Johnson-Kuhn, and Haaga 2007).

The impact of this dangerous creation on the physical and human wellbeing alarmed numerous eyewitnesses and triggered exceptional open strategic discord. Various researchers and policymakers have found that significant family instruction rates are related to relatively moderate paces of population growth. We recommended that significant open doors ease populace weights ensure more prominent access to family training, especially for women. The subsequent open arrangement of banter has sparked an evaluation of how the birth rate affects family preparation (Cochrane, 2009).

The unstable development of the human population in the 19th and 2oth centuries resulted from an overall significant decline in mortality, rather than an expansion in birth rates. The rate of young children dying tumbled almost one in three in most of the world. This rate of mortality was contrasted with one in hundred in today's most well-established social orders and one in 10 in lowpaid nations. Among the wealthiest countries, birth rates are quickly balanced to restore equilibrium between births and passages and to speed up population growth by below 1 percent a year. The total number of children intended for a regenerative lady has dropped from about seven to under two financially induced social orders. However, comparable decreases in birth levels have not seen sharp declines in mortality levels in the most vulnerable countries.

Furthermore, in the majority of the world, there has been a substantial increase in population growth, the disparity between the average birth rate and the usual death rate. In less affluent and less able nations, population growth has been especially notable in spending money on social and educative administrations. The combined impacts of these forces seem to indicate that if adequate measures are not implemented, the rich and poor intake is possible to make beyond what is not as far away.

These realities suggest that improving family training is the way to ensure an economic pace of population development. Since 2006, countless researchers have focused on the effects of family training, especially the young lady's instruction on maturity, mortality, and the development of populations. The essential purpose behind these examinations consisted of deciding whether their relationship with various powers, which directly affect the timeline, is causally linked to the standard connection of low wealth and high levels of family education. The different connection between the skills of women and richness, for example, may not be related to instruction accordingly, but may necessarily reveal that social orders sincerely seek to teach women additionally concern themselves with the support from the government of women and look at controlling maturity to ensure their welfare (Jejeebhoy, 2005).

\subsection{Socio-economic factors connecting family education and training}

Financial experts have proposed that population control problems be based on the original thoughts 
of the organic market. They argued that the number of children a couple expects is determined by the capacity to keep under pressure, by the variables that choose family sizes and by the couples' willingness to achieve their objectives. Those factors determine the limit on achieving wealth goals such as marriage age, the strength of the individual, her fertility and customs, and taboos that affect intercourse. Women we went to first sexual intercourse at a younger age have more childbearing skills than women who marry late. A wife's readiness to foresee a pregnancy or to express it in its entirety will be affected by nutrition and the history of the disease. The disadvantages of group sex for a blessed post-work period or the decreasing period of a lady's pregnancy during the bosom. The failure to ovulate during breast treatment also reduces the time a lady can become pregnant.

The desire for young people (two or three children want) is also the result of complex calculations. In general, financial analysts concentrated on children's net contributions to family income and material support from the government. Young people usually get help from the family's economic government through shallow salary networks at a very young age. Kids take care of a younger baby, releasing their mothers into work in fields or stores. Minor children are often supportive of the crowding of animals and kitchen gardens under the watchful eye.

Moreover, children provide guardians of their mature ages with monetary security. As salaries and desires regularly increase, guardians often look for fewer children and offer more and better education. Employment advertises higher pay network incentive preparation expectations and societal forecasts as an expectation of societal achievement. As a result, families will generally have fewer young people with an increased livelihood but will put significantly more into maintaining and training every child. The costs of equipping young girls with donations and wedding parties affect young people's curiosity.

A couple's desire to reach their desired family size is somewhat contingent upon access to contraceptives. A unique mind-boggling collection of customs and emotional forces determines the decision to regulate ripeness. Social expectations that value prominent families make fruitfulness impediment a questionable decision for others, couples live in traditional social orders. The couple's social status and its comparative self-governance with relatives and different individuals from the more distant kin, community, or network influence the decisions that are made. The examination writing has focused on the effect that proper instruction has on ladies' dynamic self-rule of contraception and wealth decisions. The paper sets that ladies who are better educated are not only slowly taught about the open alternatives to reduce fruitfulness but are also better prepared to manage these topics with partners and more distant families. Specific consideration has been given to the impact of the instructive status on the receptiveness of correspondence among a pair.

Once again, scientists have argued that the typical instructive fulfillment of individuals from a network, and the increasing qualities and goals; thus, influence desired family size and contraceptive access. Such specialists have proposed that the value of the system littler, more select groups, be slowly instructed. They also argued that programs that promote present-day value are increasingly robust options to limit resources.

\section{Conclusion}

Family life preparation is fit to make a substantial contribution to improving families as an integral unit of the general public to serve their extensive work. Education in family life is of fundamental importance, mainly when the population of the country turns out to be gradually diverse in terms of race, ethnicity, and language. This could make a significant difference in human society, mainly because it concerns the explosion and control of the population. Family life education material is indispensable when it comes to living a happy life and fostering population reduction. Governments need to pay attention to it as well as individuals to strengthen good family relationships, which can contribute to national growth. 


\section{Recommendations}

The following recommendations are made;

1. Family life education should be included in the country's curriculum, to be considered in some levels of education, notably higher education.

2. However, education in family life should be in the form of semi-formal or adult learning to uneducated people of old age, perhaps especially in rural areas.

3. Incentives should be offered in the form of affirmation to those who follow the teachings to emerge more of their interest in it.

4. The content to be studied (in Family Life Education) should include; effects of family size on living standards, the relationship between and between family members, and another family.

5. Adolescence Growth and Development is an integral part of education regarding family life. Strengthened educational efforts should be undertaken in areas such as self-understanding, relationship with parents, roles and responsibilities, management of emotions and stress, dating and courtship, growth in adolescence and sexuality development, and others.

6. Training in family life should be paying more attention to moral concerns and cultural values. This will succeed in fostering a morally healthy culture.

7. Family life education should be given ample visibility using mass media, religious institutions, and community leaders.

\section{References}

Adediwura, A. A., \& Tayo, B. (2007). Perception of teacher's knowledge, attitude, and teaching skills as a predictor of academic performance in Nigerian secondary schools. Educational Research and Reviews, 2 (7), 165-171.

Alazzi, F. K. (2013). Jordanian students' attitudes toward social studies education. The Journal of International Social Research, 6 (24),227-236.

Bledsoe, C. H., Casterline, J. B., Johnson-Kuhn, J. A. \& Haaga, J. G. (2007). Critical Perspectives on Schooling and Fertility in the Developing World. Washington, DC: National Academy Press.

Chiappetta, E. L \& Koballa Jr. T. R. (2006). Science Institution in the middle and Secondary Schools. Developing Fundamental Knowledge and Skills for Teaching; $\quad$ 6th ed; Pearson: Merill Prentice Hall; Ohio.

COCHRANE, S. H. (2009). Fertility and Education: What Do We Really Know? Baltimore: Johns Hopkins University Press.

Elster, D. (2007). Students' interests- The German and Austrian ROSE Survey. Journal of Biological Education, 42(1), 5-11. Retrieved from http://dx.doi.org/10./o8o/o0219266.2007.965610o.

International Planned Parenthood Federation (IPPF) (1985). Family Life Education: A Guide for Youth Organisations. London. As cited in Birdthistle \& VinceWhitman, 1997.

Jejeebhoy, S. J. (2005). Women's Education, Autonomy, and Reproductive Behavior. Oxford: Clarendon Press.

Kuhl, P. K., Tsao, F.-M., \& Liu, H.-M. (2003). Foreign-language experience in infancy: Effects of short-term exposure and social interaction on phonetic learning. Proceedings of the National Academy of Sciences, U.S.A., 100, 9096-9101. doi:10.1073/pnas.1532872100

U.N. (2018). Universal Declaration of Human Rights. U.N.G.A. Res. 217A (III), 3(1) U.N. G.A.O.R. Res. 71, U.N. Doc.

Yasin, N.M. (2015) Corruption a Contemporary Challenge to Development and National Security in Nigeria. A paper presented at $5^{\text {th }}$ National Conference on Security, National Integration, and challenges of development in Nigeria, held at Usmanu Danfodiyo University, Sokoto Nigeria, between $3^{\text {rd }}$ and $6^{\text {th }}$ August 2015 . 